\title{
Size-adapted Parallel and Hybrid Parallel Robots for Sensor Guided Micro Assembly
}

\author{
Kerstin Schöttler, Annika Raatz and Jürgen Hesselbach \\ Technische Universität Braunschweig, Institute of Machine Tools and Production \\ Technology (IWF), Langer Kamp 19 B, D-38106 Braunschweig
}

Germany

\section{Introduction}

Miniaturized products and components are part of today's daily life. The comfort and security of automobiles is increased by use of micro sensors and actuators. Electronic devices, such as mobile phones and MP3-players, have reached very small sizes and miniaturized medical instruments facilitate endoscopic surgery.

Due to the advantages of micro technological solutions, such as small dimensions and low weight, Micro Systems Technology (MST) is worldwide considered a key technology of the $21^{\text {st }}$ century. The new NEXUS market analysis forecasts a yearly growth of the world markets of $16 \%$ for products based on MST (Wicht \& Bouchaud, 2005).

Miniaturization and simultaneous function integration are leading to increased requirements regarding production technology as a result of scaling effects, technical and assembly related problems (van Brussel et al., 2000). For MST products, micro assembly uncertainties in the range of a few micrometers or even less than one micrometer are required.

\subsection{Approaches to meet the requirements for micro assembly}

At present industrial applications for micro assembly predominantly incorporate systems which were originally developed for 2D chip assembly in semi-conductor back-end production. They can be classified into three groups according to their attainable assembly uncertainty. Most of the positioning units of the first class are pick-and-place machines based on Cartesian axes with uncertainties between $30 \mu \mathrm{m}$ and $60 \mu \mathrm{m}$ at $3 \sigma$. The second group, die-bonding machines, reaches pick-and-place uncertainties of $10 \mu \mathrm{m}$ to $12 \mu \mathrm{m}$ at $3 \sigma$ by means of high-precision linear drives, high-resolution camera systems as well as systems for controlling and compensating for influences caused by changing temperatures. Ultraprecision die-bonders form the third class. They can be regarded as special machines for specific applications which were developed for the assembly of micro-optical components, optical fibres and especially for flip-chip assembly. They reach assembly or pick-and-place uncertainties of about $1 \mu \mathrm{m}$ at $3 \sigma$. These low uncertainties can only be achieved with the help of special camera systems and positioning strategies. At present, these assembly uncertainties are always tied to a highly customized design of the assembly system adjusted Source: Parallel Manipulators, Towards New Applications, Book edited by: Huapeng Wu, ISBN 978-3-902613-40-0, pp. 506, April 2008, I-Tech Education and Publishing, Vienna, Austria 
to the requirements of the products. This way the assembly uncertainties described are reached at the expense of a very low flexibility (Raatz \& Hesselbach, 2007).

For the design of micro assembly systems it is necessary to gain a high product flexibility of the assembly units. Solutions that provide enough flexibility to reconfigure the system design need to be found. Here, modularity is the key when striving for high flexibility of the number of quantities, product variants and manufacturing base. The precision robot represents the central component within the assembly system. Some fundamental techniques to lower the uncertainty of the precision robot and the assembly system are choosing an adequate kinematic structure, developing size adapted handling devices, integrating ultra-precision machine elements and/or using sensor guidance (Fig. 1).

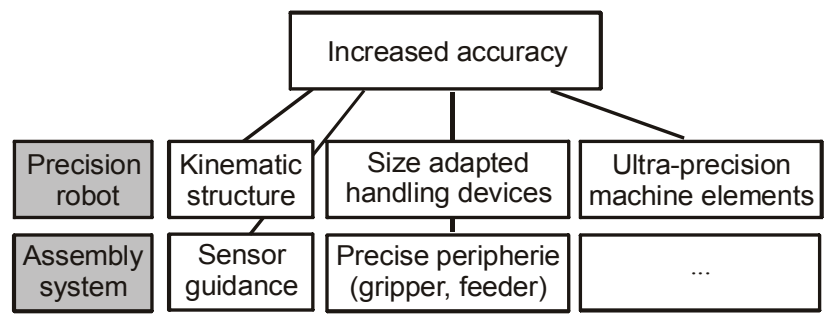

Fig. 1. Approaches to meet the requirements of accuracy (Raatz \& Hesselbach, 2007)

\subsection{Kinematic structures}

Robots can be classified in terms of their kinematic structure into serial, parallel and hybrid (serial/parallel) robots. Most industrial robots are based on a serial structure between the frame and the working platform. All joints of open kinematic chains have a single degree of freedom (DOF) and are active, i.e. they are actuated. The serial structure offers in principle a large workspace in relation to the size of the robot as well as a high orientation range. The relatively large moved masses are a disadvantage of serial structures regarding the dynamics and accuracies of the robot, since each drive must be moved along with the entire kinematic chain. In micro assembly, large moved masses lead to massive construction of the frames and the robot links related to the size of the assembled parts.

Parallel robots are based on closed kinematic chains, i.e. they have several guiding chains between the base frame and the working platform, which provide a high structural stiffness. It is possible to install all drives in a fixed frame or at least to locate them nearby the frame, which results in low inertia. Drive positioning errors or tolerances in the legs are not necessarily added. Usually they partially compensate each other and only affect the positioning uncertainty of the end effector to a small extent.

Parallel robots are well suited for highly precise handling operations, due to their high structural stiffness with low moved masses at the same time. Compared to serial robots, the miniaturization of a parallel robot is much easier because all joints are passive. In addition the passive joints offer the potential for integrating flexure hinges as ultra-precision machine elements. The small workspace compared to the robot dimensions does not become severe in micro assembly tasks due to the size of the objects.

Combining a parallel structure with a serial structure the limited and position dependent mobility of the end effector can be overcome. For example by integrating a serial rotational axis into the working platform of a parallel robot, the end effector can be very well oriented. 


\subsection{Robots for micro assembly}

A number of commercial robot manufacturers and many research institutions are developing robots which have sufficient positioning uncertainties for micro assembly tasks. Serial, parallel and hybrid robot structures are used. Most serial robots for micro assembly use a Cartesian structure. Often they incorporate modular precision linear axes. In nearly all cases, direct measuring systems are used in order to rule out inaccuracies due to mechanical play. The repeatability of those linear axes lies typically between $0.1 \mu \mathrm{m}$ and $1 \mu \mathrm{m}$. Some manufacturers and researchers claim that robots build with these axes reach an overall repeatability of $1 \mu \mathrm{m}$. A typical exponent of this class of robots is the Sysmelec Autoplace 411 (Fig. 2) (Hesselbach et al., 2005). Another solution for micro assembly robots are conventional Scara robots in combination with redundant high-precision axes in order to reach a high resolution. This approach is always combined with additional sensors to achieve a good repeatability (Höhn, 2001).

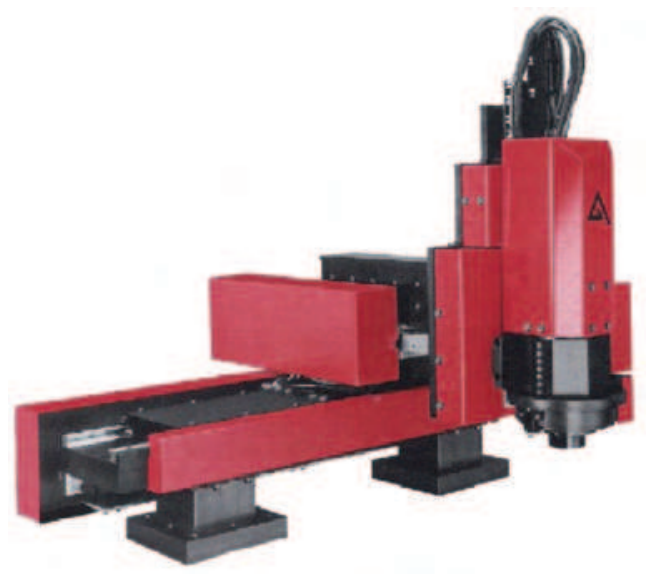

Fig. 2. Serial robot Sysmelec Autoplace 411 with Cartesian structure

The development of size-adapted robots is another solution of robots for micro assembly. Saving costs is only possible by reducing the footprint of an assembly system due to the demand of a clean room environment for the production of MST products. In recent years, the reduction of size and costs of micro production systems has been widely discussed in various papers. Most of these concepts relate to one of the two general groups explained in the following.

The first group consists of piezo driven, small walking micro robots and handling machines. These autonomous robots are suitable for positioning small objects such as the MINIMAN of (Fatikow, 2000), a handling device for samples in a scanning electron microscope. On the one hand, these micro robots are very promising for new trends such as nano assembly. By using autonomous robots, difficulties occur regarding the coordination and interaction of these robots, movement on rough surfaces and energy supply.

The second group describes cost-efficient, size-adapted handling devices, which fill the gap between piezo driven, small walking micro robots and conventional robots. A possible solution for this strategy is to determine the highest degree of miniaturization of conventional robot technology, using innovative, miniaturized machine parts. With these 
size-adapted handling devices, in the range of several centimeters to a few decimeters, easily scalable and highly flexible production technology can be designed. Examples of sizeadapted handling devices are the parallel robot structures Delta ${ }^{3}$ and Sigma 6 from (Clavel et al., 2005) and the pocket delta from (Coudourey et al., 2006).

This chapter presents a description of four size-adapted robot mechanisms based on parallel and hybrid structures. For three robot mechanisms, the structures are first designed with conventional joints and replaced by flexure hinges as ultra-precision machine element later on.

Furthermore, sensor guided assembly processes of hybrid micro systems are explained on the basis of one robot structure. Thus, the integration of sensor information into the robot control as well as the relative sensor guidance applied in the system will be presented. The positioning uncertainty and the assembly uncertainty of the process are described by means of an example of an assembly process.

\section{Size-adapted parallel and hybrid robot structures}

Various size-adapted parallel, parallel hybrid and serial hybrid robots for precision assembly were developed at the IWF. The main objective to develop size-adapted robot structures was to adapt the size of the robot cell to the size of the products. At the same time a good repeatability for highly precise micro assembly processes should be reached through the development of parallel and hybrid robot structures.

First, a functional model of a planar robot micaboe (see section 2.2) with a parallel structure and $3 \mathrm{DOF}$ for movement in the $\mathrm{x}-\mathrm{y}$ plane and $1 \mathrm{DOF}$ as a serial lifting table for movement in z-direction was implemented. Second, a spatial parallel hybrid robot structure micaboh (see section 2.3) with 6 DOF was designed. Then, a spatial parallel robot structure, Triglide (see section 2.4), based on a parallel structure with 3 DOF and one serial rotational axis was realized.

These three robots were enhanced by integrating flexure hinges (see section 2.1) as ultraprecision machine elements and named micabos, micabohs and Triglides. With this machine elements, the conventional joints of the robot structures are replaced.

Based on the experiences with the above mentioned robot structures, the robot micabof, which provides 4 DOF for part handling and, as an advanced structure, the micabo ${ }^{\mathrm{f} 2}$ (see section 2.5), which provides 4 DOF for part handling and 1 additional DOF for focusing a vision sensor, were developed as planar serial hybrid robot structures.

\subsection{Pseudo-elastic flexure hinges}

One way to increase the accuracy of assembly systems is to enhance the positioning accuracy of the robot itself. Typical problems of parallel structures are the high number of joints and joints with more than one DOF. Backlash, friction and slip-stick effects in conventional joints often decrease the overall precision of the robot. As a result of the natural lack of the above mentioned disadvantages in flexure hinges, replacing conventional joints by flexure hinges seems to be a promising way to increase the accuracy of robots. Since flexure hinges gain their mobility exclusively from a deformation of matter, the attainable angle of rotation is limited. In order to achieve high life cycles of the hinges, the deformation should remain in the elastic part since plastic deformation normally induces defects in the material leading to an earlier crack failure (Hesselbach et al., 2004b). 
The developed flexure hinges consist of a pseudo-elastic shape memory alloy (SMA). This material offers larger reversible strains than other materials, e.g. spring steel or thermoplastics, which are commonly used for flexure hinges. Due to the large reversible strains of SMA, deflections of the hinges of $\pm 30^{\circ}$ are possible. This approach offers the potential to design robots with high accuracy and resolution and with a sufficiently large workspace for micro assembly tasks (Hesselbach et al., 2004a).

SMA exists in austenite and martensite phases, depending on the temperature or the applied stress. The temperature and stress values for stable phases mainly depend on the basic material, their different alloy contents and the thermo-mechanical treatment of the material. The thermally induced phase transformation of SMA (one way effect) is typically used in applications in which the SMA device is used as an actuator. We use the stress induced phase transformation which offers large reversible strains (super-elasticity). Figure 3 shows a stress-strain diagram of pseudo-elastic SMA loaded with uniaxial tensile stress. In its initial condition, the material is in its austenitic phase at room temperature. First, it deforms linear elastic under load. With increasing loads a stress-induced transformation of austenite into martensite is initiated at the pseudo-yield stress $R_{\text {pe. The }}$ phase transformation is accompanied by large pseudo-elastic strains $\varepsilon_{\text {pe }}$ with nearly constant stresses. The pseudo-elastic strain is reverted at a lower stress $\sigma_{\mathrm{r}}$ with a stress hysteresis. Since pseudo-elastic strains are reversible, the specimen completely recovers to its undeformed shape. These strains are often called pseudo-elastic because the reversible deformation is caused by a reversible phase transformation and not only due to a translation of atoms out of their former equilibrium position.

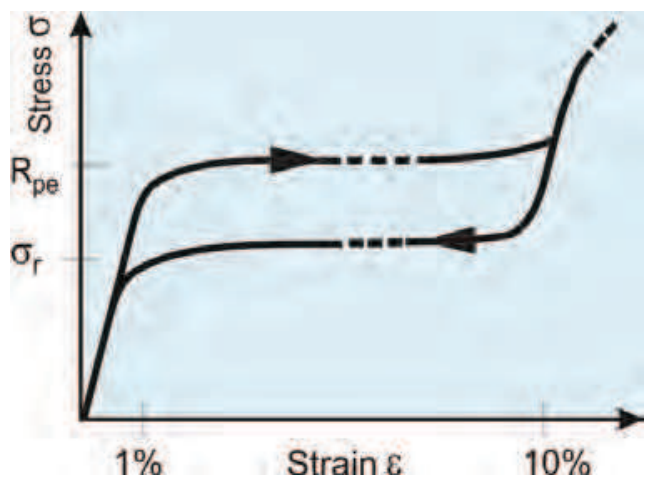

Fig. 3. Stress-strain diagram of shape memory alloy

A pseudo-elastic CuAlNiFe single crystal SMA is used for the design of flexure hinges because of its superior machinability and extremely large reversible strains up to $17 \%$. The uniaxial stress-strain diagram of a CuAlNiFe single crystal has two pseudo-elastic stress plateaus, differing slightly from the example shown in Figure 3, but equivalent in principle. The first plateau, which is the area of interest, has a yield stress of about $R_{p e}=200 \mathrm{~N} / \mathrm{mm}^{2}$ and reversible strains of $\varepsilon=10 \%$.

A variety of different geometries of flexure hinges are proposed in the literature. They are designed in monolithic or hybrid processes allowing for up to 3 degrees of freedom (DOF) (Smith, 2000), (Paros \& Weisbord, 1965). When designing flexure hinges for robots optimisation criteria are high accuracy and a large workspace of the robot. For the three 
robots micaboes, micabohs and Triglides (described in section 2.2, 2.3 and 2.4) pseudo-elastic flexure notch hinges with $\mathrm{R}=15 \mathrm{~mm}$ and $\mathrm{h}=0.15 \mathrm{~mm}$ are used. These geometrical dimensions are an optimum between small kinematic deviations compared to the kinematics of an ideal rotational joint and small occurring strains. The pseudo-elastic material can be modelled with a material model by Prandtl-Reuss if the deflection curve is calculated analytically (Howell \& Midha, 1995), (Hesselbach \& Raatz, 2000) or with a multilinear elastic material model using the FEM tool ANSYS. With the chosen geometry and geometrical dimensions maximal strains are $\varepsilon=2.1 \%$ at deflections of $20^{\circ}$ and $\varepsilon=4.2 \%$ at $30^{\circ}$.

\subsection{Planar parallel robot structures micabo $^{\mathrm{e}}$ and micabo ${ }^{\mathrm{es}}$ with $3 \mathrm{DOF}$ and one serial z- axis}

The planar parallel robot structure micaboe (Fig. 4 left) provides 3 DOF. Three linear drives move the platform and the gripper with three guiding chains in $x$-y-direction and enable a rotation $\varphi$ around the z-axis. The movement in the direction of the z-axis is performed by an additional elevation platform. The robot is driven by three piezoelectric stick-slip drives with a smallest step size of $5 \mathrm{~nm}$ and is equipped with linear encoders with a resolution of $0.1 \mu \mathrm{m}$. First, the passive rotary joints were built with conventional ball bearings. A repeatability of $4 \mu \mathrm{m}$ with $3 \sigma$ is reached, according to (EN ISO 9283, 1999). The characteristics of the robot micabo are shown in Table 1.

Figure 4 (right) shows the planar parallel robot micaboes with 3 DOF in which the 6 conventional rotational joints are replaced by 6 flexure hinges. The motors, step sizes and resolution of the linear encoders are equal to the micaboe.
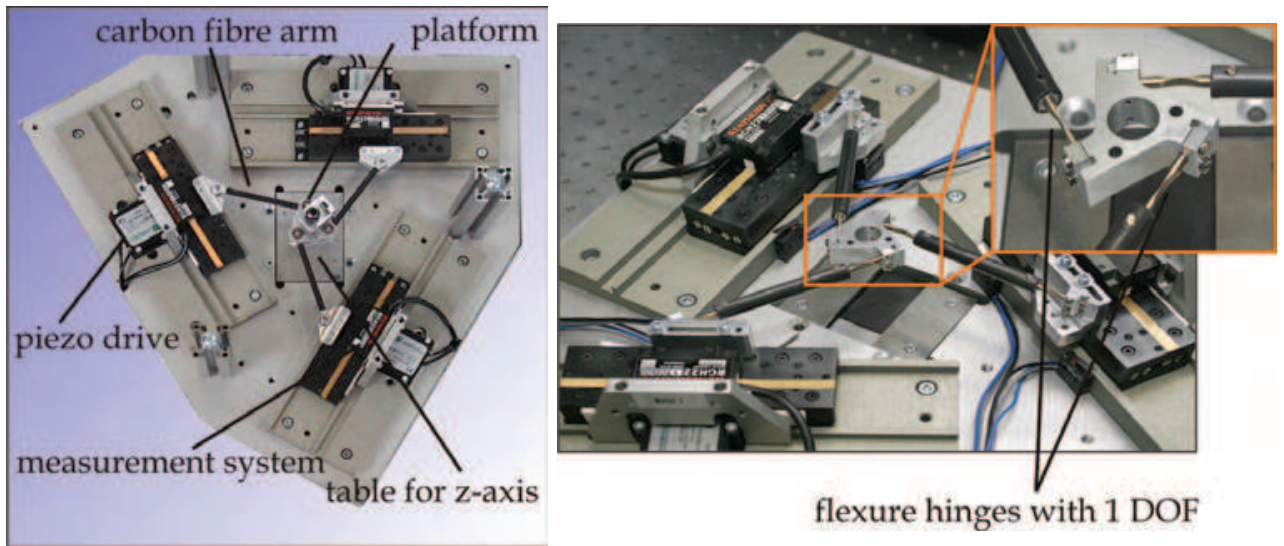

Fig. 4. Planar parallel robot structures micaboe (left) and micaboes (right)

With an assumed maximal angular deflection of $\pm 30^{\circ}$ at the hinges and maximal motion ranges of the drives of $70 \mathrm{~mm}$ the workspace of the robot is $40 \times 40 \mathrm{~mm}^{2}$. If flexure hinges with conventional spring steel are used, the angular deflection is restricted to $\pm 5^{\circ}$. In this case the resulting workspace of the structure is about twenty times smaller compared to the workspace using pseudo-elastic flexure hinges. A repeatability of $1 \mu \mathrm{m}$ with $3 \sigma$ is reached with the flexure hinges. The characteristics of the robot micaboes are shown in Table 1 as well. 


\begin{tabular}{|c|c|c|}
\hline Performance Data & micabo & micaboes $^{\mathbf{e}}$ \\
\hline Max. velocity of the linear drives & \multicolumn{2}{|c|}{$0.23 \mathrm{~m} / \mathrm{s}$} \\
\hline Max. velocity of the end effector & $0.15 \mathrm{~m} / \mathrm{s}$ \\
\hline Payload & \multicolumn{2}{|c|}{$0.1 \mathrm{~kg}$} \\
\hline Smallest step size & \multicolumn{2}{|c|}{$5 \mathrm{~nm}$} \\
\hline Resolution of linear encoders & \multicolumn{2}{|c|}{$0.1 \mu \mathrm{m}$} \\
\hline Footprint & \multicolumn{2}{|c|}{$440 \times 440 \mathrm{~mm}^{2}$} \\
\hline Workspace translational & $40 \times 40 \mathrm{~mm}^{2}$ \\
\hline Repeatability & $4 \mu \mathrm{m}$ & $1 \mu \mathrm{m}$ \\
\hline
\end{tabular}

Table 1. Characteristics of the robots micabo and micaboes (Raatz, 2006)

\subsection{Spatial parallel hybrid robot structures micabo ${ }^{\text {h }}$ and micabo ${ }^{\text {hs }}$ with 6 DOF}

Six degree of freedom in $x_{-}, y_{-}, \mathrm{z}$-direction and around the Euler angles $\psi, \theta, \varphi$ are realized with the spatial parallel hybrid robot structure micaboh (Fig. 5). Six translational high resolution piezo drives are used. The movement of the end effector can partly be decoupled from the drives by integrating planar sub chains inside a spatial structure and, at the same time, by defining certain dependencies between the geometric parameters. Two drives slide on one axis and are coupled in one planar sub chain. The sub arm links have the same length. The three sliding axes are parallel to the vertical axis of the coordinate system. The position of the lower drives defines the inclination $(\theta, \varphi)$ of the working platform as a result of the structural configuration. The distance between upper and lower drives defines the position of the working platform in the horizontal plane $(x, y, \psi)$, and an equal movement of all drives leads to a movement in z-direction only (Hesselbach et al., 1997). Therefore, the structure is ideal for assembly tasks with a main working plane parallel to the base frame (Raatz, 2006).

Experimental measurements with the robot structure micaboh with conventional joints lead to a worse repeatability than expected, with insufficient reproducibility. Reasons for the worse results of the repeatability measurements were largely attributed to the ball joints which were poorly adjustable (Hesselbach et al., 2004b).

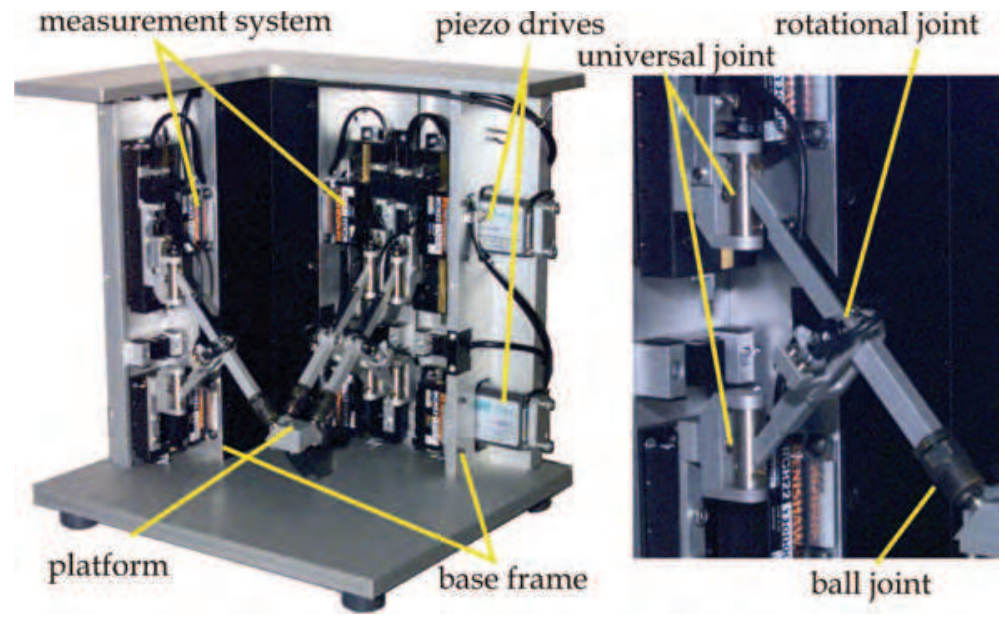

Fig. 5. Spatial parallel hybrid robot structure micaboh 
As further development the spatial parallel hybrid robot structure micabohs (Fig. 6) is designed with spatial flexure hinges. Therefore, joints with one, two and three DOF have to be replaced. One planar sub chain consists of two links which are connected with a rotational joint $(1 \mathrm{DOF})$. Each sub chain is connected with the drive over a universal joint (2 $\mathrm{DOF}$ ) and to the working platform over a ball joint (3 DOF). The universal joints and the ball joints are realized by a spatial combination of flexure hinges with 1 DOF. A workspace of $40 \times 40 \times 18 \mathrm{~mm}^{3}$ without additional inclination of the platform is realized with the micabohs (Raatz, 2006). In Table 2 the characteristics of the robot structures micaboh and micabohs with conventional joints and flexure hinges are depicted.

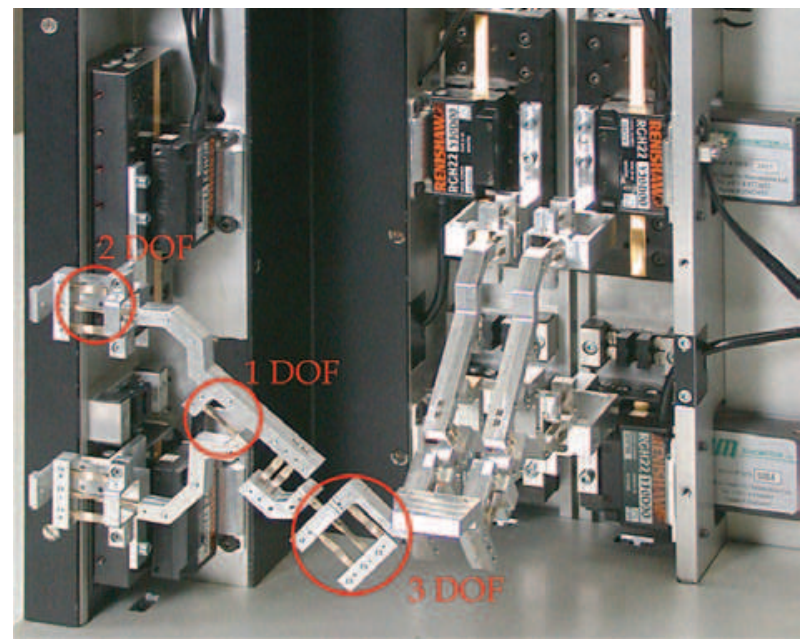

Fig. 6. Spatial parallel hybrid robot structure with flexure hinges micabohs

In accuracy measurements, a repeatability of $3 \mu \mathrm{m}$ was measured for the micabohs. But these values have to be taken very carefully since the compliant robot is prone to vibrations (in zdirection with higher amplitudes than the repeatability values). This is due to the slip-stick effects of the piezo drives. Additionally, the structure has an inhomogeneous stiffness in the $\mathrm{x}-, \mathrm{y}-$ and $\mathrm{z}$ - directions and the working platform is not symmetrically supported via the sub chains. As a consequence the damping mechanism of the spatial structure is not as good as the one of the planar parallel robot micaboes.

\begin{tabular}{|c|c|c|}
\hline Performance Data & micabo $^{\text {h }}$ & micabohs $^{\text {ha }}$ \\
\hline Max. velocity of the linear drives & \multicolumn{2}{|c|}{$0.23 \mathrm{~m} / \mathrm{s}$} \\
\hline Max. velocity of the end effector & \multicolumn{2}{|c|}{$0.1 \mathrm{~m} / \mathrm{s}$} \\
\hline Smallest step size & \multicolumn{2}{|c|}{$5 \mathrm{~nm}$} \\
\hline Resolution of linear encoders & \multicolumn{2}{|c|}{$0.1 \mu \mathrm{m}$} \\
\hline Footprint & \multicolumn{2}{|c|}{$270 \times 240 \mathrm{~mm}^{2}$} \\
\hline Workspace translational & $40 \times 40 \times 18 \mathrm{~mm}^{3}$ & $40 \times 40 \times 18 \mathrm{~mm}^{3}$ \\
\hline Repeatability & - & $3 \mu \mathrm{m}$ \\
\hline
\end{tabular}

Table 2. Characteristics of the robots micaboh and micabohs (Raatz, 2006) 


\subsection{Spatial parallel robot structures Triglide and Triglide ${ }^{\mathrm{s}}$ with $3 \mathrm{DOF}$ and one serial rotational axis}

The spatial parallel robot structure Triglide (Fig. 7) with 3 DOF ( $x-, y-$ and $z$-direction) was developed by the IWF and the Robert Bosch company as the main component of an assembly cell for micro assembly purposes. Three linear drives are arranged star-shaped in the base plane at intervals of $120^{\circ}$. This leads to a nearly triangle-shaped workspace. The working platform is connected to each drive by two links forming a parallelogram. This yields to translational movements of the platform and keeps the platform plane parallel to the base plane. An additional rotary axes is integrated serial into the working platform. The orientation of the working platform is therefore only limited by the gripper size and supply wires. This structure is very rigid and drive errors are reduced because the ratio of the "platform movement" to the "drive movement" is always <1 (Hesselbach et al., 2005). In this configuration, the resolution of the electrical linear motors with linear encoders is $0.125 \mu \mathrm{m}$. A repeatability of $0.9 \mu \mathrm{m}$ with $3 \sigma$ is reached with conventional joints.

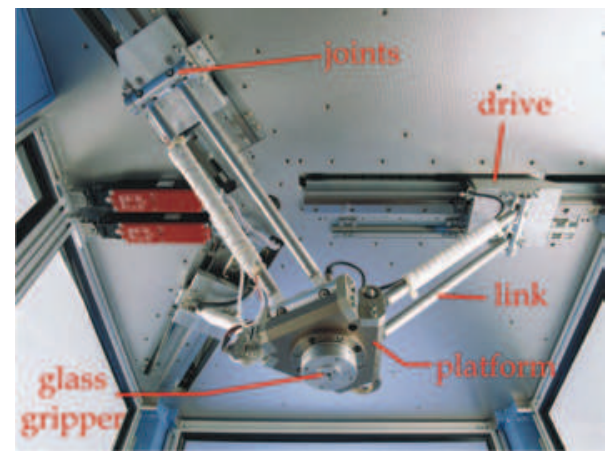

Fig. 7. Spatial parallel robot structure Triglide

Figure 8 shows the compliant spatial robot Triglides with 3 DOF and 6 integrated combined flexure hinges. The motors, footprint, workspace and the resolution of the linear encoders are equal to the Triglide.

For spatial mechanisms, flexure hinges with more than 1 DOF have to be designed. Those flexure hinges are realised by a spatial combination of flexure hinges with 1 DOF. A problem of compliant mechanisms, especially of spatial mechanisms, is their tendency to vibrate. Actually, the flexure hinges act as springs without any damping component, except for the inner damping of the deformed material. Figure 8 shows an example of increasing stiffness and optimising the distribution of occurring forces by a suitable design of a combined flexure hinge. Torsional moments can better be absorbed and transformed into tension and compression forces, since the hinges are arranged in a parallel and angular pattern (Hesselbach et al., 2004a).

Although the workspace is nearly triangular, a cube with a dimension of $112 \times 112 \times 112 \mathrm{~mm}^{3}$ would fit into the workspace with the present configuration. If flexure hinges made of spring steel were used, the resulting workspace would be hundred times smaller then the workspace of the present design with pseudo-elastic flexure hinges. A repeatability of $0.3 \mu \mathrm{m}$ with $3 \sigma$ is reached with the flexure hinges. In Table 3 , the characteristics of Triglide and Triglides are listed. 


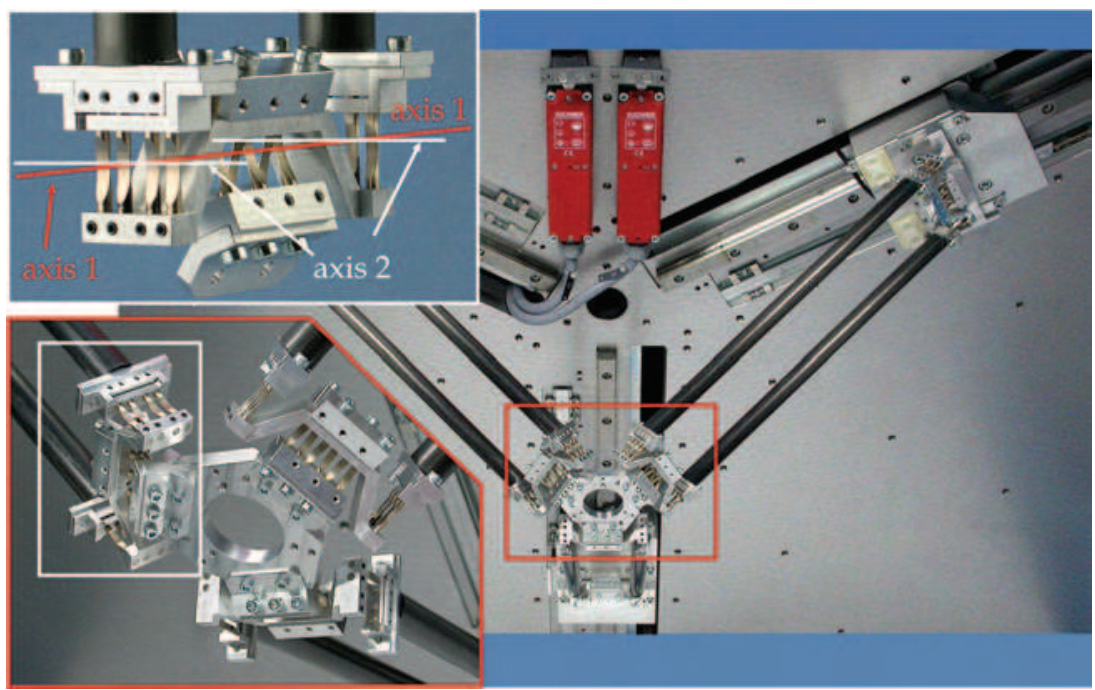

Fig. 8. Spatial parallel robot structure with flexure hinges Triglides

\begin{tabular}{|c|c|c|}
\hline Performance Data & Triglide & Triglides $^{\mathbf{s}}$ \\
\hline Max. velocity of the linear drives & \multicolumn{2}{|c|}{$0.2 \mathrm{~m} / \mathrm{s}$} \\
\hline Max. velocity of the end effector & \multicolumn{2}{|c|}{$0.2 \mathrm{~m} / \mathrm{s}$} \\
\hline Payload & \multicolumn{2}{|c|}{$1 \mathrm{~kg}$} \\
\hline Resolution of linear encoders & \multicolumn{2}{|c|}{$0.125 \mu \mathrm{m}$} \\
\hline Footprint & \multicolumn{2}{|c|}{$1280 \times 980 \mathrm{~mm}^{2}$} \\
\hline Workspace translational & \multicolumn{2}{|c|}{$112 \times 112 \times 112 \mathrm{~mm}^{3}$} \\
\hline Repeatability & $0.9 \mu \mathrm{m}$ & $0.3 \mu \mathrm{m}$ \\
\hline
\end{tabular}

Table 3. Characteristics of the robots Triglide and Triglides (Raatz, 2006)

\subsection{Planar serial hybrid robot structures micabo ${ }^{f}$ and micabo ${ }^{\mathrm{f} 2}$ with $4 \mathrm{DOF}$}

Another hybrid robot is the planar serial hybrid robot micabof with 4 DOF (Fig. 9 left). For movement in the xy-plane, two parallel linear axes with a resolution of $0.1 \mu \mathrm{m}$ are used. Inside the robot head, two serial mounted drives for motion in $\mathrm{z}$-direction and around the $\mathrm{z}$ axis are located. Furthermore, the robot head is designed hollow for the integration of a camera. The micabof carries a 3D vision sensor (Tutsch \& Berndt, 2003) which is integrated in the hollow robot head. This sensor is used for a sensor guided micro assembly with high accuracy. The workspace of the robot measures $120 \times 200 \times 15 \mathrm{~mm}^{3}$.

This hybrid robot structure combines the advantages of parallel and serial robotic structures. The parallel linear axes in the xy-plane offer high stiffness. A high accuracy is reached in this plane because of the combination of high resolution encoders and high precision motors. With the help of the serial drives in the robot head, a higher range of rotation than in a fully parallel structure is possible. In accuracy measurements, the micabof reached a repeatability of $2.6 \mu \mathrm{m}$ (see the characteristics of the robot in Table 4). 

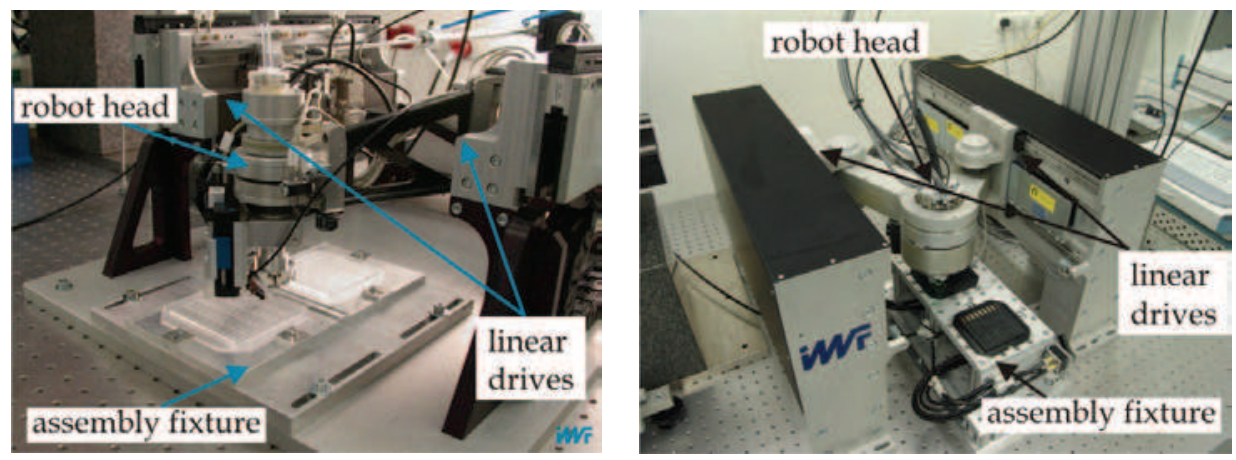

Fig. 9. Serial hybrid robot structures micabof (left) and micabof2 (right)

Although a good repeatability is reached with the micabof, a self-induced vibration of the parallel linear drives occur, which is caused by the interaction between air bearings and linear drives. Neither the usage of additional dampers for the air bearings, nor optimisation of the control could eliminate this vibration. The parallel drives move around the desired position with a deviation of $\pm 1 \mu \mathrm{m}$ because of this vibration. Furthermore, the workspace does not offer enough flexibility for part feeding, clamping different work pieces or extending the flexibility with two additional rotational drives in the workspace for $3 \mathrm{D}$ assembly operations. This leads to a demand for a redesign that reaches the required repeatability in the range of $1 \mu \mathrm{m}$ and, at the same time, offers more flexibility by a larger workspace with better accessibility.

The robot micabof2 (Fig. 9 right) has 4 DOF for part handling and one additional DOF for focus adjustment of the former mentioned 3D vision sensor. Two parallel linear drives impart motion in the xy-plane. Each of them is connected to a slide that is coupled to the arms of the structure through rotational bearings. A hollow axis between the arms takes up the robot head, which is designed like a cartridge and forms the tool center point (TCP). Inside the robot head, two drives are installed. One of them moves a platform with a gripper and the other one moves the 3D vision sensor (Simnofske, 2005). The workspace is enlarged to $160 \times 400 \times 15 \mathrm{~mm}^{3}$ with better accessibility than before. In accuracy measurements, the micabo $^{\mathrm{f} 2}$ reached a repeatability of $0.6 \mu \mathrm{m}$ (Table 4 ).

\begin{tabular}{|c|c|c|}
\hline Performance Data & micabo $^{\text {f }}$ & micabo $^{\text {f2 }}$ \\
\hline $\begin{array}{c}\text { Max. velocity of the linear drives } \\
(\mathrm{x}, \mathrm{y})\end{array}$ & \multicolumn{2}{|c|}{$0.1 \mathrm{~m} / \mathrm{s}$} \\
\hline $\begin{array}{c}\text { Max. acceleration of the linear drives } \\
(\mathrm{x}, \mathrm{y})\end{array}$ & \multicolumn{2}{|c|}{$2 \mathrm{~g}$} \\
\hline Payload & \multicolumn{2}{|c|}{$0.2 \mathrm{~kg}$} \\
\hline Resolution of linear encoders & \multicolumn{2}{|c|}{$0.1 \mu \mathrm{m}$} \\
\hline Footprint & $480 \times 600 \mathrm{~mm}^{2}$ & $500 \times 600 \mathrm{~mm}^{2}$ \\
\hline $\begin{array}{c}\text { Workspace translational / rotary } \\
\text { angle }\end{array}$ & $120 \times 200 \times 15 \mathrm{~mm}^{3} / \pm 45^{\circ}$ & $160 \times 400 \times 15 \mathrm{~mm}^{3} / \pm 180^{\circ}$ \\
\hline Repeatability & $2.6 \mu \mathrm{m}$ & $0.6 \mu \mathrm{m}^{2}$ \\
\hline
\end{tabular}

Table 4. Characteristics of the robots micabo ${ }^{\mathrm{f}}$ and micabo ${ }^{\mathrm{f} 2}$ 


\subsection{Results of the development of size-adapted parallel and hybrid robot structures}

In the previous sections, the development of four size-adapted robot structures, each with two different designs of the kinematic chain, was presented. Diverse requirements for the workspace, accuracies and flexibility can be fulfilled as a result of the different structures.

A small footprint is realized with the planar parallel robot structures micabo $/$ micabos $^{\text {es }}$

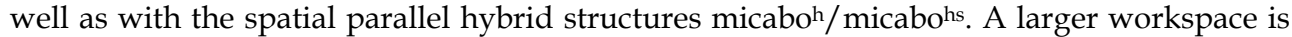
offered by the spatial parallel robot structures Triglide/Triglides and by the planar serial hybrid robot structures micabof $/$ micabo $^{\mathrm{f}}$. Therefore, the footprint is larger than that those of the micabo and micaboh.

The integration of flexure hinges as ultra-precision machine elements into the size-adapted robot structures micaboes, micabohs and Triglides leads to a better repeatability than with conventional joints. All robot structures presented here offer a sufficient repeatability for micro assembly. The most applicable robot structure can be chosen, depending on the assembly task.

The precision robot with its high accuracy is an important part of an assembly system for micro assembly tasks. Besides the precision robot, most assembly tasks require the use of additional sensors with high resolutions and measurement accuracies to reach a low assembly uncertainty. Furthermore, the technology of the gripper, the joining process and the adjustment of the assembly place influence the reachable assembly uncertainty. In section 3, an example of sensor guided micro assembly by use of the planar serial hybrid robot structure micabo ${ }^{\mathrm{f} 2}$ is described. The reachable assembly uncertainty is shown on the basis of an assembly process.

\section{Sensor guided micro assembly}

The assembly of hybrid micro systems typically demands assembly uncertainties in the range of a few micrometers. To achieve this high accuracy, the precision robot is supported by at least one sensor. Sensors for micro assembly can be optical sensors with resolutions in the range of a micrometer and below or force sensors with resolutions much below $1 \mathrm{~N}$.

In the described example, the planar serial hybrid robot structure micabo ${ }^{\mathrm{f} 2}$ is supported by a $3 \mathrm{D}$ vision sensor and a $6 \mathrm{D}$ force sensor. The $3 \mathrm{D}$ vision sensor possesses a repeatability of $0.22 \mu \mathrm{m}$ in $x_{-}, 0.29 \mu \mathrm{m}$ in $\mathrm{y}$ - and $0.83 \mu \mathrm{m}$ in z-direction. The field of view covers $11 \mathrm{~mm}$ in length and $5.5 \mathrm{~mm}$ in width. A beam splitter is arranged in front of a miniature camera, which directs the images of two perspectives to the CCD chip of the camera (Berndt, 2007).

With this vision sensor, 3D micro assembly tasks can be implemented. A positioning uncertainty lower than $0.5 \mu \mathrm{m}$ can be reached with the combination of robot micabo ${ }^{\mathrm{f} 2}$ and $3 \mathrm{D}$ vision sensor. The reachable positioning uncertainty depends on the design of the assembly group and varies between $0.5 \mu \mathrm{m}$ and $1 \mu \mathrm{m}$.

The $6 \mathrm{D}$ force sensor features a force measuring range ( $x-, y$ - and z-direction) of $\pm 12.5 \mathrm{~N}$ with a resolution of $0.0125 \mathrm{~N}$. A measuring range of $\pm 125 \mathrm{Nmm}$ with a resolution of $0.0625 \mathrm{Nmm}$ for torques is given by the manufacturer. A defined joining force can be guaranteed by using the $6 \mathrm{D}$ force sensor for the implementation of a force controller inside the robot control. The robot micabof 2 is controlled by a real-time control system that is described in section 3.1. A description of the two methods for sensor guided micro assembly is given in section 3.2 and the chosen method for the presented assembly process is presented in section 3.3. The results of the sensor guided assembly process are shown in section 3.4. 


\subsection{Robot control}

A real-time system is used to control the robot. The hardware of the control system features a PowerPC750 digital signal processor (DSP) running at $480 \mathrm{MHz}$, a digital I/O board, analog I/O boards, an encoder board and a serial I/O board. For programming, the control codes in "Matlab/ Simulink" and " $\mathrm{C}$ " are used. An open architecture control is realized that can deal with almost every robotic system with up to six axes. It consists of "structure specific" and "not structure specific" blocks (Fig. 10).

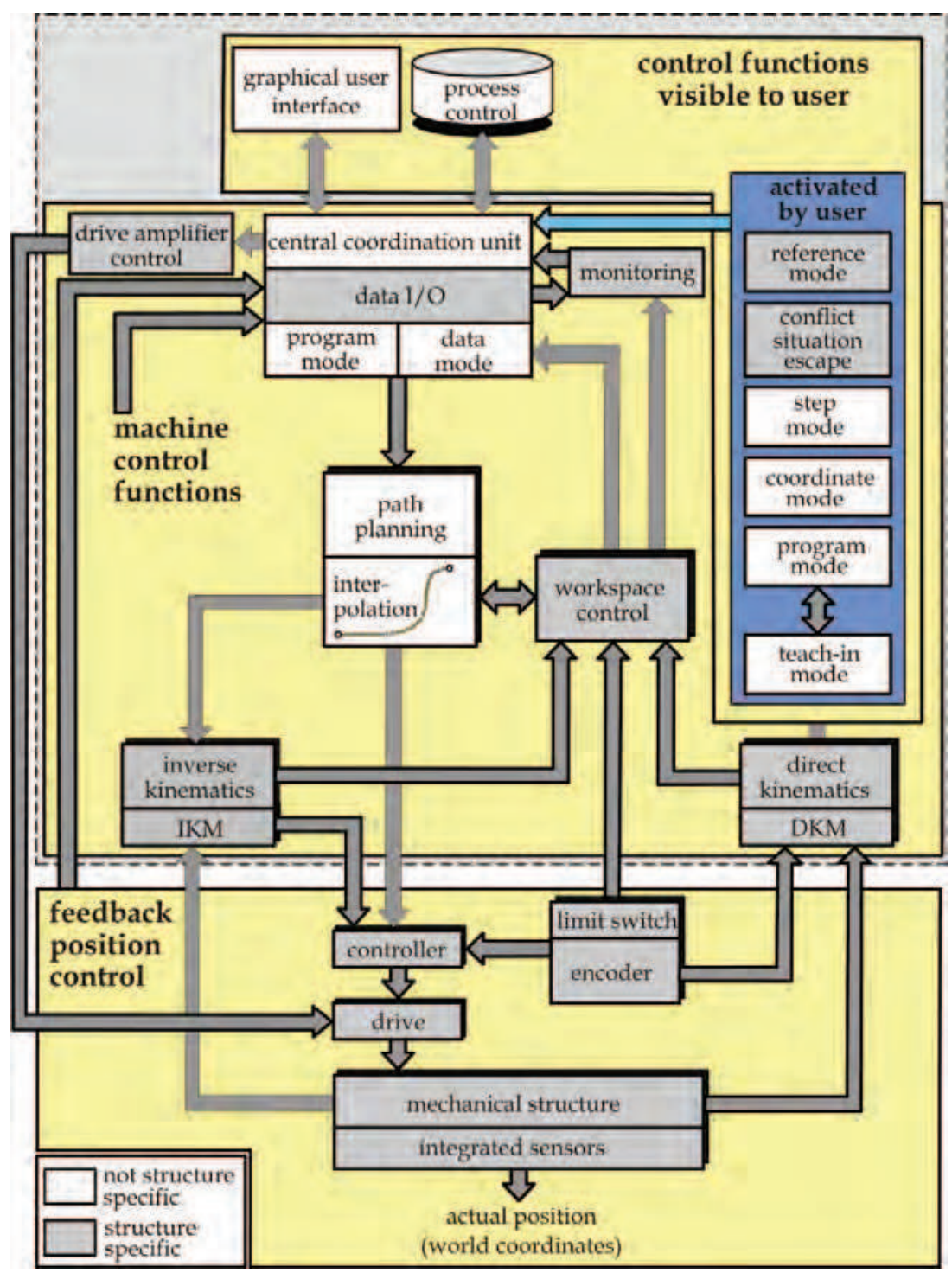

Fig. 10. Robot control concept 
For use with a special robot, the "structure specific" blocks of the control have to be adapted to this robot structure. "Structure specific" blocks include inverse and direct kinematics, workspace control, monitoring, drive amplifier control, feedback position control as well as the allocation of data inputs and outputs. The "not structure specific" blocks, e.g. path planning and interpolation, do not have to be adapted.

\subsection{Sensor guidance in micro assembly processes}

Sensor guidance means that a feedback of position and/or force information is used to direct the positioning of the handling device during an assembly process. The information is given by optical or force sensors. Two different ways of data acquisition and data processing lead to the distinction of "absolute sensor guidance" and "relative sensor guidance".

In a (micro) assembly process with absolute sensor guidance, the measurements of the handled part and the measurements of the assembly position on a substrate are carried out separately. The measurements are related by transformation of the sensor information into the world coordinate system. A position difference is calculated and carried out by the handling device. Only one position correction loop is possible with this method, which is used e.g. for pick-and-place assembly of SMD components.

With the method of relative sensor guidance, a simultaneous measurement of the handled part and the assembly position on a substrate is performed. The sensor information is transformed in the world coordinate system, too, and a position difference is calculated. The position correction can be performed in as many loops as desired. Naturally, as few correction loops as possible are carried out to ensure a low cycle time.

Relative sensor guidance is used for micro assembly tasks in this example. Sensor information from the vision sensor must be transmitted to the robot control. Therefore, two different control loops are used in the robot control (Fig. 11).

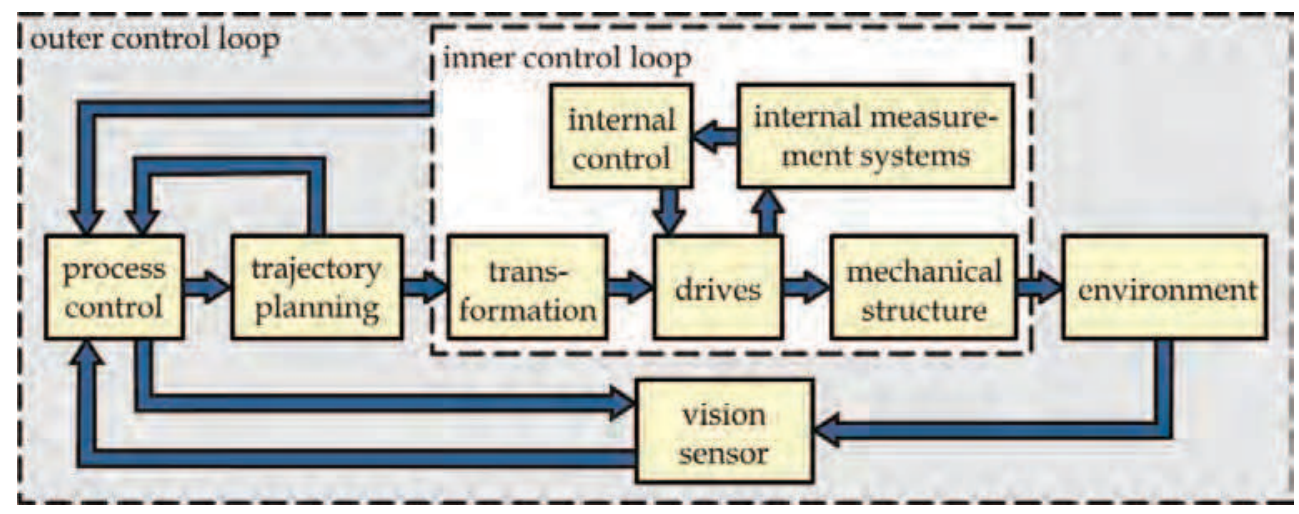

Fig. 11. Control loop with the use of sensor information

The process control gives commands to the robot control and demands information from the vision sensor system. The internal control loop works in a clock frequency of $5 \mathrm{kHz}$. The outer control loop contains the vision sensor, which gives relative position information to the process control. A resulting vector of the last desired position from the robot control and the relative position vector from the vision system is calculated inside the process control and transmitted to the robot control. 
At present, the sensor guidance works in a so called "look-and-move" procedure. This means that the robot's movement stops before a new measurement of the vision sensor is done and a new position correction is executed.

\subsection{Example of assembly process}

As an example, the assembly of a micro linear stepping motor, according to the reluctance principle, is described. The motor parts are mainly manufactured with micro technologies. One assembly task is the joining of guides on the surface of the motor's stator element. In Figure 12 (left) the assembly group of two guides on a stator is shown. Figure 12 (right) shows the view of the 3D vision sensor of the assembly scene.

Circular positioning marks on the stator and guides are used by the $3 \mathrm{D}$ vision sensor for the relative positioning process. The reachable assembly uncertainty depends on the arrangement of the positioning marks and the length of the handled part. It is essential that the distances between the positioning marks are as large and the part length as small as possible.
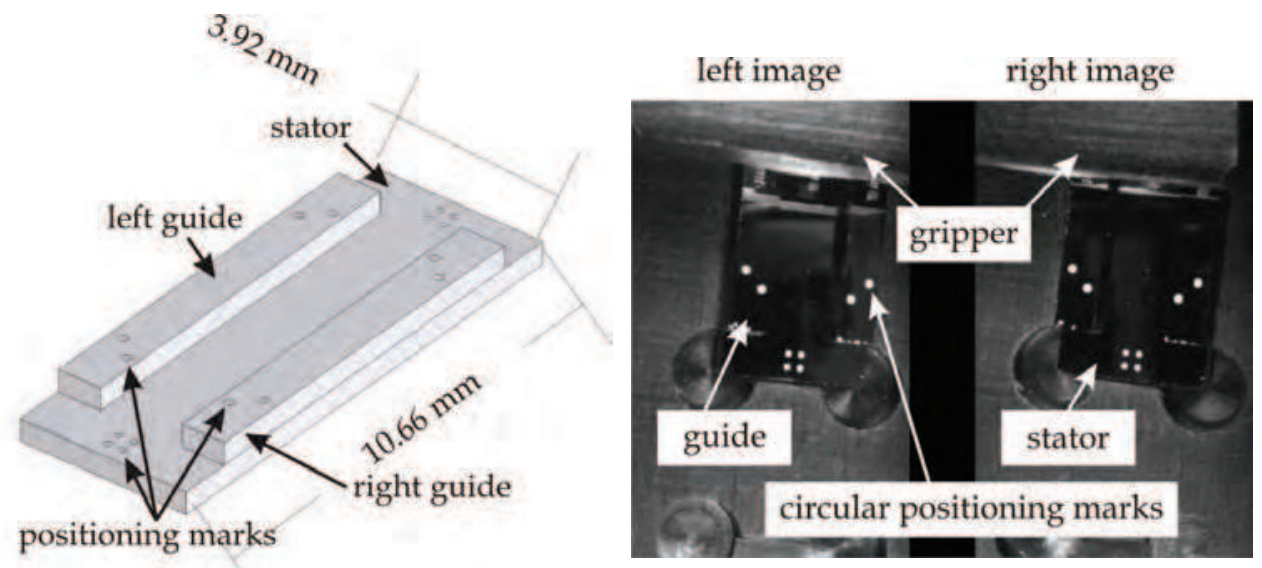

Fig. 12. Micro linear stepping motor - principle (left) and sensor view (right)

The sequence of the assembly process is shown in Figure 13. First, the robot moves over a stator element and checks the positioning marks. If the marks can be recognized, the robot moves over one left guide and checks the positioning marks, too. If the guide is recognized, it is picked up with a vacuum gripper by use of sensor information for a repeatable gripping process. Afterwards, the robot moves with the left guide over the stator and starts the relative positioning process. In this process, a measurement and calculation of a relative positioning vector is followed by the comparison with a limit value. If the relative position vector is larger then the limit value, a position correction is executed with the robot. Otherwise, the left guide is placed on the stator by use of the previously mentioned 6D force sensor to assure a defined contact force and reproducible process parameters. Cyanoacrylate is used for the bonding process. 
Afterwards the relative positioning process is repeated for the right guide. During the assembly process, according to the method of relative sensor guidance, a limit value of $0.8 \mu \mathrm{m}$ can be reached with the combination of the $3 \mathrm{D}$ vision sensor and the robot micabof 2 .
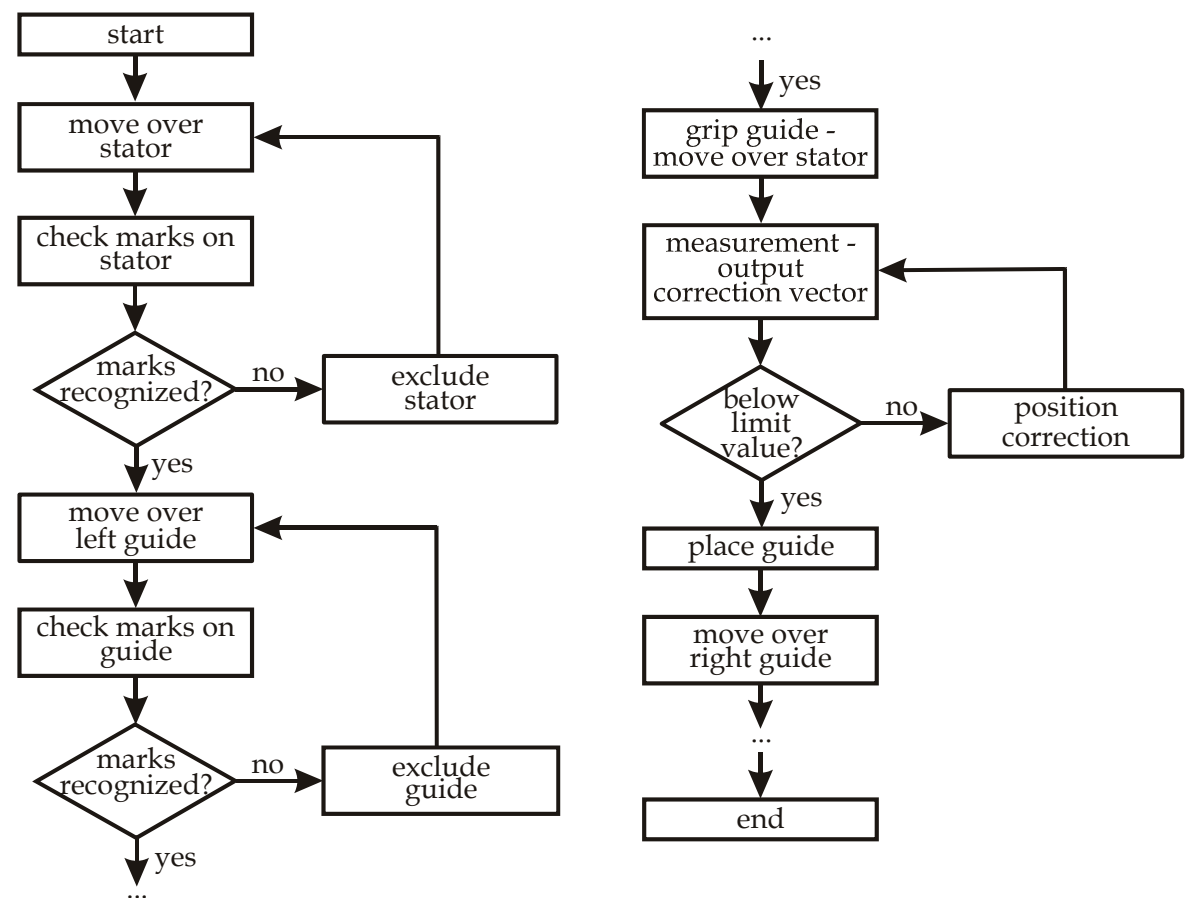

Fig. 13. Sequence of the assembly process

\subsection{Results of the sensor guided assembly process}

To quantify the precision assembly process, two terms were defined - positioning uncertainty and assembly uncertainty. According to (DIN ISO 230-2, 2000) the positioning uncertainty is the combination of the mean positioning deviation and the double standard deviation.

For precision assembly processes the term positioning uncertainty refers to the reached relative position between the two parts of the assembly group before the bonding process is carried out (in this case the guide is above the stator and is not in contact with it). The term assembly uncertainty describes the relative position between the assembled parts, measured after the assembly process has been completed. This is the combination of the mean assembly deviation and the double standard deviation, too.

Positioning marks are used as an inspection criterion. They are used for quality control of the parts before the process and during the process for the relative sensor guidance and evaluating the positioning uncertainty. After the process the positioning marks are used for evaluating the assembly uncertainty. During the process only one end of the assembled parts can be measured because the gripper covers half of the guide and the stator (see Fig. 12 
right). Therefore, the $3 \mathrm{D}$ vision sensor observes only the visible sides of the assembled parts. This means that the measured positioning error and the resulting positioning uncertainty are only determined by the visible part side. After the process, both ends of the assembly group can be inspected and the overall assembly deviation can be measured. The assembly uncertainty is calculated from the deviations. This value is comprised of the overall errors during the assembly of the micro system.

An assembly uncertainty of $38 \mu \mathrm{m}$ and a positioning uncertainty of $0.82 \mu \mathrm{m}$ are reached for the assembly process. The difference between assembly uncertainty and positioning uncertainty is a result of the relatively long part length of $10.66 \mathrm{~mm}$. A small angular deviation causes a positioning error (in xy-direction). This error is larger at the side of the part which is invisible during the positioning process than the error on the visible side. With a greater part length, this positioning error will be higher than with smaller parts. Furthermore, deviations occurring during the bonding process cause an increased assembly error. Figure 14 shows the positioning uncertainty and figure 15 the assembly uncertainty of the assembled groups. The circles in the diagrams show the radius of the uncertainties.

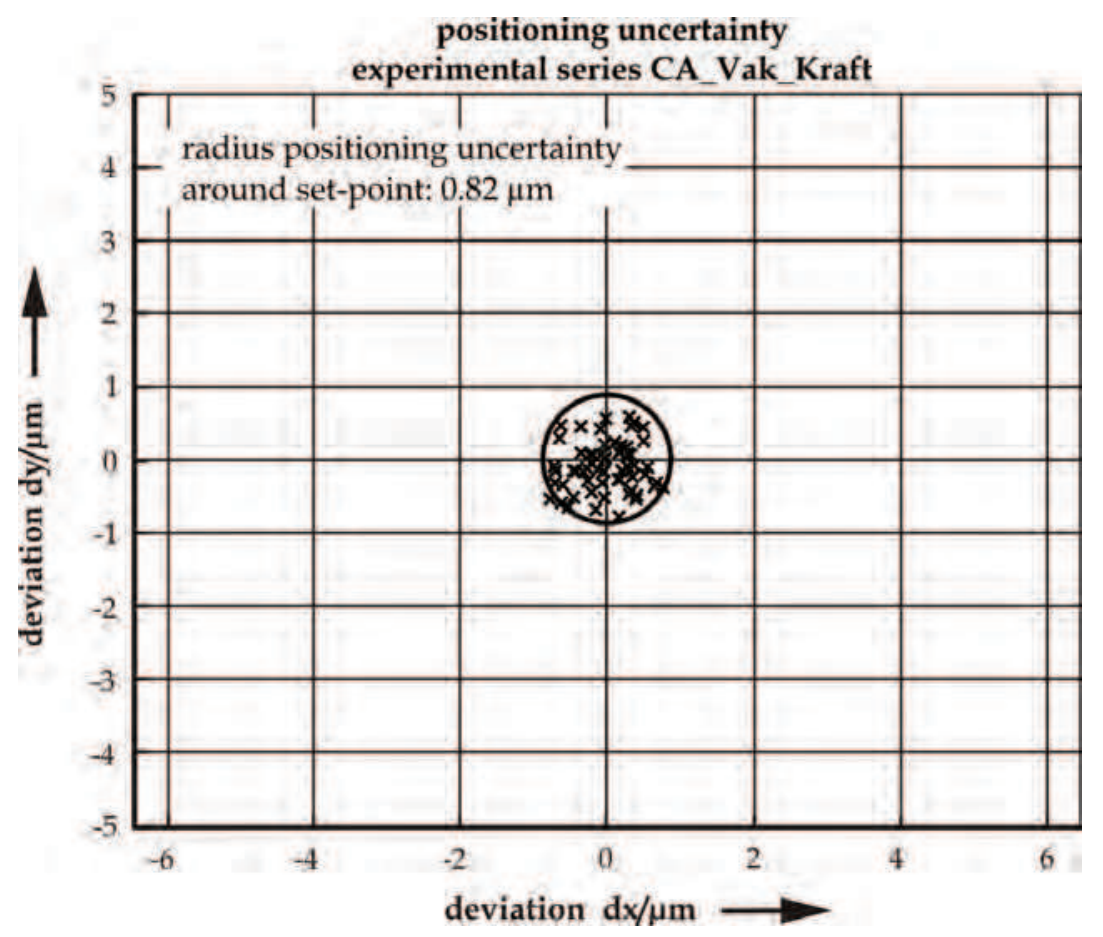

Fig. 14. Reached positioning uncertainty

In another assembly task, assembly uncertainties of $25 \mu \mathrm{m}$ were reached with another design of the assembly group. Therefore, the distance between the positioning marks has been enlarged. A positioning uncertainty and a limit value of $0.5 \mu \mathrm{m}$ was reached with this arrangement of the positioning marks. This demonstrates the potential for further improvement of the assembly uncertainty. 


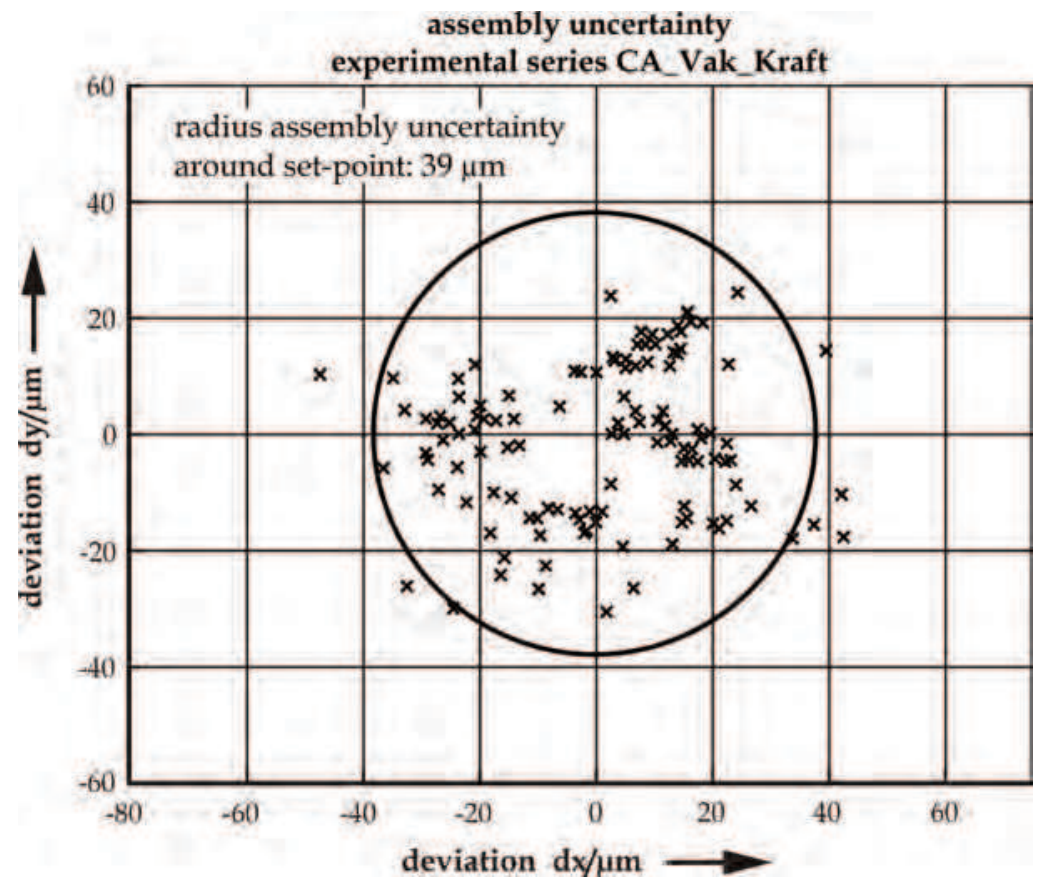

Fig. 15. Reached assembly uncertainty

\section{Conclusion}

Micro assembly tasks demand low assembly uncertainties in the range of a few micrometers. This request results from the small part sizes in the production of MST components and the resulting small valid tolerances. Since precision robots represent the central component of an assembly system, an appropriate kinematic structure is crucial. These kinematic structures can be serial, parallel or hybrid (serial/parallel). Although serial structures can be used for micro assembly, they have large moved masses and need a massive construction of the frame and robot links to obtain an appropriate repeatability.

Therefore, some size-adapted parallel and hybrid parallel robot structures were presented in the previous sections. Very good repeatabilities were reached with the presented robots due to the chosen structures, the miniaturized design and the use of flexure hinges as ultraprecision machine components.

Besides the precision robot, most assembly tasks require the use of additional sensors with high resolutions and measurement accuracies to reach a low assembly uncertainty. Therefore, optical and/or force sensors are used for sensor guided micro assembly processes.

The terms "absolute sensor guidance" and "relative sensor guidance" were introduced. Both methods offer an enhancement of the accuracy within micro assembly processes. The "relative sensor guidance" promises a lower positioning and assembly uncertainty because of the user defined number of position correction loops. Therefore, relative sensor guidance was used in the presented example for micro assembly. 
With the use of relative sensor guidance, positioning uncertainties below $0.5 \mu \mathrm{m}$ can be reached. The assembly uncertainty has to be further improved to fulfil the demand for assembly uncertainties in the range of a few micrometers. Therefore, the design of the product and positioning marks as well as the gripping and joining technology has to be examined in future developments.

\section{References}

Berndt, M. (2007). Photogrammetrischer 3D-Bildsensor für die automatisierte Mikromontage, Schriftenreihe des Institutes für Produktionsmesstechnik, No. 3, Shaker Verlag, ISBN 978-3-8322-6768-1, Aachen

van Brussel, H. ; Peirs, J. ; Delchambre, A. ; Reinhart, G. ; Roth, N. ; Weck, M. \& Zussman, E. (2000). Assembly of Microsystems, Annals of CIRP, Vol. 49, No. 2, pp. 451-472

Clavel, R.; Helmer, P.; Niaritsiry, T.; Rossopoulos, S.; Verettas, I. (2005). High Precision Parallel Robots for Micro-Factory Applications, Robotic Systems for Handling and Assembly - Proc. of 2nd International Colloquium of the Collaborative Research Center 562, Fortschritte in der Robotik Band 9, Shaker Verlag, ISBN 3-832-3866-2, Aachen, pp. 285-296

Coudourey, A.; Perroud, S.; Mussard, Y. (2006). Miniature Reconfigurable Assembly Line for Small Products, Proc. Third International Precision Assembly Seminar (IPAS'2006), Springer Verlag, ISBN 0-387-31276-5, Berlin, pp. 193-200

DIN ISO 230-2 (2000). Prüfregeln für Werkzeugmaschinen, Teil 2: Bestimmung der Positionierunsicherheit und der Wiederholpräzision der Positionierung von numerisch gesteuerten Achsen, Beuth Verlag, Berlin

EN ISO 9283 (1999). Industrieroboter: Leistungskenngrößen und zugehörige Prüfmethoden. Beuth Verlag, Berlin

Fatikow, S. (2000). Miniman. In: Mikroroboter und Mikromontage, p. 277, Teubner Verlag, ISBN 3-519-06264-X, Stuttgart - Leipzig

Hesselbach, J.; Plitea, N. ; Thoben, R. (1997). Advanced technologies for micro assembly, Proc. of SPIE, Vol. 3202, pp. 178-190

Hesselbach, J.; Raatz, A. (2000). Pseudo-Elastic Flexure-Hinges in Robots for Micro Assembly, Proc. of SPIE, Vol. 4194, pp. 157-167

Hesselbach, J. ; Raatz, A. \& Kunzmann, H. (2004a). Performance of Pseudo-Elastic Flexure Hinges in Parallel Robots for Micro-Assembly Tasks, Annals of CIRP, Vol. 53, No. 1, pp. 329-332

Hesselbach, J.; Wrege, J.; Raatz, A.; Becker, O. (2004b) Aspects on Design of High Precision Parallel Robots, Journal of Assembly Automation, Vol. 24, No. 1, pp. 49-57

Hesselbach, J. ; Wrege, J. ; Raatz, A. ; Heuer, K. \& Soetebier, S. (2005). Microassembly Approaches to Meet the Requirements of Accuracy, In: Advanced Micro $\mathcal{E}$ Nanosystems Volume 4 - Micro-Engineering in Metals and Ceramics Part II, Löhe, D. (Ed.) \& Haußelt, J. (Ed.), pp. 475-498, Wiley-VCH Verlag, ISBN 3-527-31493-8, Weinheim

Höhn, M. (2001). Sensorgeführte Montage hybrider Mikrosysteme, Forschungsberichte iwb, Herbert Utz Verlag, ISBN 3-8316-0012-0, München

Howell, L.L.; Midha, A. (1995). Parametric Deflection Approximations for End-Loaded, Large-Deflection Beams in Compliant Mechanisms, Journal of Mechanical Design, Vol. 117, No. 3, pp. 156-165 
Paros, J.M. ; Weisbord, L. (1965). How to Design Flexure Hinges, Machine Design, Vol. 25, pp. 151-156

Raatz, A. (2006). Stoffschlüssige Gelenke aus pseudo-elastischen Formgedächtnislegierungen in Parallelrobotern, Vulkan Verlag, ISBN 3-8027-8691-2, Essen

Raatz, A. \& Hesselbach, J. (2007). High-Precision Robots and Micro Assembly, Proceedings of COMA '07 International Conference on Competitive Manufacturing, pp.321-326, Stellenbosch, South Africa, 2007

Simnofske, M. ; Schöttler, K. ; Hesselbach, J. (2005). Micabo ${ }^{2}$ - robot for micro assembly, Production Engineering, Vol. 12, No. 2, pp. 215-218

Smith, S.T. (2000). Flexures - Elements of Elastic Mechanisms. Gordon \& Breach Science Publishers, ISBN 90-5699-261-9, Amsterdam

Tutsch, R.; Berndt, M. (2003). Optischer 3D-Sensor zur räumlichen Positionsbestimmung bei der Mikromontage, Applied Machine Vision, VDI-Report No. 1800, Stuttgart, pp. 111118

Wicht, H. \& Bouchaud, J. (2005). NEXUS Market Analysis for MEMS and Microsystems III 2005-2009, mst news, Vol. 5, 2005, pp. 33-34 


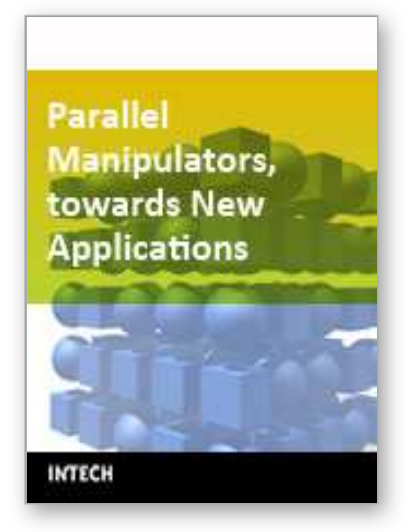

\author{
Parallel Manipulators, towards New Applications \\ Edited by Huapeng Wu
}

ISBN 978-3-902613-40-0

Hard cover, 506 pages

Publisher I-Tech Education and Publishing

Published online 01, April, 2008

Published in print edition April, 2008

In recent years, parallel kinematics mechanisms have attracted a lot of attention from the academic and industrial communities due to potential applications not only as robot manipulators but also as machine tools. Generally, the criteria used to compare the performance of traditional serial robots and parallel robots are the workspace, the ratio between the payload and the robot mass, accuracy, and dynamic behaviour. In addition to the reduced coupling effect between joints, parallel robots bring the benefits of much higher payload-robot mass ratios, superior accuracy and greater stiffness; qualities which lead to better dynamic performance. The main drawback with parallel robots is the relatively small workspace. A great deal of research on parallel robots has been carried out worldwide, and a large number of parallel mechanism systems have been built for various applications, such as remote handling, machine tools, medical robots, simulators, micro-robots, and humanoid robots. This book opens a window to exceptional research and development work on parallel mechanisms contributed by authors from around the world. Through this window the reader can get a good view of current parallel robot research and applications.

\title{
How to reference
}

In order to correctly reference this scholarly work, feel free to copy and paste the following:

Kerstin Schoettler, Annika Raatz and Juergen Hesselbach (2008). Size-adapted Parallel and Hybrid Parallel Robots for Sensor Guided Micro Assembly, Parallel Manipulators, towards New Applications, Huapeng Wu (Ed.), ISBN: 978-3-902613-40-0, InTech, Available from:

http://www.intechopen.com/books/parallel_manipulators_towards_new_applications/sizeadapted_parallel_and_hybrid_parallel_robots_for_sensor_guided_micro_assembly

\section{INTECH}

open science | open minds

\section{InTech Europe}

University Campus STeP Ri

Slavka Krautzeka 83/A

51000 Rijeka, Croatia

Phone: +385 (51) 770447

Fax: +385 (51) 686166

www.intechopen.com

\section{InTech China}

Unit 405, Office Block, Hotel Equatorial Shanghai

No.65, Yan An Road (West), Shanghai, 200040, China

中国上海市延安西路65号上海国际贵都大饭店办公楼 405 单元

Phone: +86-21-62489820

Fax: +86-21-62489821 
(C) 2008 The Author(s). Licensee IntechOpen. This chapter is distributed under the terms of the Creative Commons Attribution-NonCommercialShareAlike-3.0 License, which permits use, distribution and reproduction for non-commercial purposes, provided the original is properly cited and derivative works building on this content are distributed under the same license. 